\title{
EDITORIAL
}

\section{The Journal's peer reviewing system}

As I marshalled my thoughts for this editorial, we were preparing for a forthcoming editorial board meeting at which I was to report on the preceding year's progress and activities. It is customary to analyse details of papers received and published. What was our acceptance rate? What proportion of papers did we receive from home and abroad? How was the proportion of papers concerned with human, small animal and farm animal subjects changing? How quickly did we get them through the editorial procedure?

This last consideration then caused me to pause and think of the letters I had received from anxious authors wondering what had become of the paper submitted far too long ago, and of the placatory responses I had written to authors, whether or not they were justifiably aggrieved, and to editors who might have been unpardonably tardy. If this has an overpessimistic ring, I should also mention the letters from authors congratulating editors on their thoroughness and helpfulness, and my letters to editors thanking them for excellent editorial reviews when that was warranted.

This led me to ponder the strengths and weaknesses of the peer review system, a subject that has been thoughtfully analysed by a sister journal, the New England Journal of Medicine, in its issue of 21 September 1989 (Relman \& Angell, 1989). It occurred to me that the system used by any journal, including ours, is probably shrouded in mystery to all except those who have been intimately connected with the workings of the editorial board. Each journal has its own particular system and readers may find it helpful to have the following account of how this Journal organizes its editorial and peer reviewing system.

The starting point, and the most important people in the system are the authors. They will have made a judgement about whether the Journal is a suitable vehicle for the publication of their work by reading recent issues. They should also have consulted the 'Directions to Contributors' section in a recent issue of the Journal, which clearly identifies the scope of work that is published: original work in all branches of nutrition from any country and which aims to develop nutritional concepts. Despite this seemingly broad remit, potential authors seemed, until recently, to have developed a rather narrow view of the Journal's field. Policy decisions to change this perception, to widen the scope somewhat and especially to encourage publication of good work in human, including clinical, nutrition were discussed in the Editorial of the issue of January 1989 (Gurr, 1989). Not all authors read the 'Directions to Contributors' section carefully, however, and too many papers are received in an inappropriate format with perhaps a system of referencing different from that adopted by the Journal. Such oversights inevitably prolong the time taken to get papers to a publishable state.

The British Journal of Nutrition operates with an editorial board of some thirty scientists. Of these, twenty-two are scientific editors chosen to cover, as thoroughly as possible, the areas of research of interest to the Journal, and seven are statistics editors, because the Journal has a strong policy to encourage the best possible design of experiments and the most appropriate analysis of the data.

Editors serve for a term of 6 years and are not eligible to return to the board within 1 year of retiring from a term. Their terms tend to overlap so that only a small proportion of editors is changed at any one time, thereby maintaining continuity and experience. On the retirement of an editor, the chairman, in consultation with editorial board colleagues, recommends the appointment of a new editor, usually in the same subject area or possibly 
a different one if the pattern of papers being received is seen to be changing. Scientific editors are wholly responsible for recommending to the chairman, in the form of an editorial report, whether or not a paper is acceptable for publication. Normally, they are assisted in this task by a statistics editor and one or more of a larger group of referees or editorial advisers. The latter are asked by the Journal if they will be willing to referee papers as and when requested, and they undertake to respond reasonably quickly. Their names are listed in the Journal and they may be selected directly by the editor, or the chairman may recommend names from this list to an editor who may be responsible for a paper on the borderlines of his or her expertise. Referees, by contrast, belong to a much wider group of nutrition scientists known to the chairman or individual editors. They have no specific obligation to the Journal but may be invaluable in supplying very special expertise when required.

Papers received by the office from authors are allocated a number and details of the paper and its subsequent editorial pathway are recorded in a card index. The corresponding author is sent an acknowledgement of receipt. The chairman identifies an appropriate editor and the paper is sent to the chosen editor with a covering letter that normally suggests an appropriate statistics editor. It has not been the policy of the Journal to send every paper to a statistics editor, but the matter is under discussion. Normally the editor is free to choose appropriate editorial adviser(s) or referee(s) and to notify the office accordingly so that they can be properly acknowledged in the Journal. On occasion, after preliminary discussion with the editor, the chairman or office manager will identify an adviser who is sent the paper at the same time as a copy goes to the editor. This can have the advantage of saving time. Sometimes, when it is immediately clear that the paper is not acceptable for publication, either because it describes work inappropriate for the Journal or because of its poor standard, the chairman may return the paper to the author with a covering letter explaining why the paper cannot be accepted, without sending to an editor. This ensures that editors are not burdened unnecessarily with unpublishable material, although this procedure is relatively rare.

First editors are given 7 weeks for a new paper and 5 weeks for a revised paper, and the time limit, which includes time to contact referees and statistics editors, is clearly marked on the front of the file. 'Blue cards' are supplied to editors to remind referees and statistics editors who have held papers for more than 3 weeks. Editors are asked, well in advance, if they are likely to be away for periods of longer than about 3 weeks. All these procedures are designed to ensure that papers are handled as speedily as possible, consistent with being able to edit papers with care and thoroughness.

It is the first editor's responsibility to make a final decision on a paper's acceptability and to write an editorial report. This incorporates the comments of referees and, usually, of statistics editors in a form suitable to be transmitted to the author. When the major criticisms have to do with the statistical aspects of the work, it may be more appropriate to send the statistics editor's comments as a separate report. Detailed discussion between the scientific and statistics editors is often a key element in the editorial process.

It is important for the reputation of the Journal and the advancement of good scientific research, that the tone of the report sent to the author is courteous, constructive and helpful, even when the scientific assessment of the work is exceptionally critical. Even when the decision is that the paper should be rejected outright, the Journal aims to provide a constructive editorial report so that authors, who may then wish to revise the paper for submission to another journal, can approach their task with a degree of confidence and optimism. Such rejections are usually on the grounds that the material merely repeats earlier work with some minor modification, and does not contribute to developing fundamental concepts of nutrition. It may be that the work is sound enough but the subject matter is not relevant to the Journal's interests and would be more appropriately published 
elsewhere. In some papers, the outcome of the work is too inconclusive or the results are insufficient to support the conclusions, while in others the techniques used are either inappropriate or inadequate and the results are, therefore, untrustworthy. Other papers may contain a major flaw in design or conception such that no modification of the text or production of additional data can redeem the situation. Finally, although very rare, it does sometimes occur that a paper is ethically objectionable. Papers describing work on human subjects must be approved by the Ethical Committee of the institution involved and the work must follow the guidelines in the Declaration of Helsinki (1964). Experiments on animals should be such that they could be performed under a Home Office licence if they were performed in the UK.

It is not unusual for authors to put up a spirited defence of their rejected papers. The chairman's task is to mediate. He will ask the editor to study carefully the author's arguments and consider whether he is persuaded that his original assessment was correct in the light of the author's comments. Editors always consider these matters conscientiously, but it is rare to find an editor's decision reversed and even rarer for the chairman to overrule the editor, although it can occur. There are sometimes 'difficult' papers that elicit quite opposing views from two referees, and on these occasions the chairman may be asked by the editor to make a final decision on acceptance or rejection. Sometimes, but not often, I overrule an editor's decision, and when this occurs I always explain very carefully the circumstances and the reasons for my action.

It is rare to accept a paper without any further requirements from the authors. Papers that are finally accepted usually fall into two categories: those that can be given an initial acceptance provided that the authors can make appropriate corrections and amendments; and those that will not be acceptable unless considerable corrections, modifications and even new experimental findings are supplied. This is probably the largest category, and the one that gives most work to editors in assessing the paper and to authors in revising it. The 'accept with minor modifications' category usually results in a paper that is fully acceptable after the first revision. In this case the paper then goes for 'technical editing' to ensure that the format and content are fully compatible with the Journal's style and requirements. Papers in the 'will only be acceptable after extensive modification' category may need a second and sometimes even a third revision before they are accepted. Again it is the Journal's policy to be helpful and constructive, and this may sometimes involve an editor in suggesting alternative interpretations of the authors' results or, when the authors have submitted two or more papers in a 'series', suggesting how these might be combined.

Sometimes a paper can evoke unusual passions in an otherwise normally calm and rational editor. The chairman may then need to carry out surgery to the report before transmission to the author. Remarks of the 'this paper isn't even suitable for papering a wall' variety are not best suited to encouraging authors to comply with requests for amendments. One copy of the paper that is sent to the editor is marked 'This copy will NOT be returned to the author' and editors can annotate this with complete freedom. It is one way an editor has of letting his or her hair down! The chairman soon becomes adept at diplomatically phrasing rejection letters even when faced with the most vitriolic of referees' comments.

After nearly 2 years as chairman of the British Journal of Nutrition, it seems to me that the most frequently recurring faults in papers that we receive are lack of clarity in presenting aims of the work, the methods used and the interpretation of results. The methods are frequently poorly described and lacking in detail. Another area of concern is a certain wordiness and lack of conciseness in the writing of the discussion, which could almost always be much shorter. This is so for native English writers: how much more difficult it is for our overseas contributors for whom English is not the mother tongue! The fact that we are publishing an ever larger proportion of papers from outside the UK is 
something that gives us great pleasure, and we are full of admiration for the facility with which many such papers are written. Others, however, can present enormous problems. Although our staff can do quite a lot with a reasonably written paper, there are times when it is simply beyond our capacity to do the rewriting necessary. It is my custom to suggest that overseas authors find a friendly neighbourhood English speaker to help them with the preparation of the typescript.

The task of the chairman is to oversee the flow of papers into and out of the office. It is very much a job of dealing with people, and one can discard the layman's idea that scientists are invariably cool, dispassionate and objective. The critical word here is invariably. An editorial board can only function well and do its job of overseeing the publication of good science if it approaches its task as objectively as possible, and this it most certainly does. Personal feelings, however, can never be eliminated, and maybe our subject would be less vibrant if they were. Authors have been known to suggest that editors and referees are the lowest forms of life and the process of scientific publication could well proceed without them (e.g. see Bishop, 1984). After a particularly 'difficult' paper has gone to and fro between editor and author several times and the editor is still taking the view that the paper is not quite ready for publication, I have sometimes taken the view that we should publish and let readers judge for themselves the quality of the work, perhaps by writing in strong terms to the correspondence column. I do not think that this procedure could possibly be adopted, as some have suggested, for the whole of the Journal's output. There would be too much chaff and too little wheat. I do, however, think it is legitimate when the paper has already been improved significantly by the editorial process.

Would the peer reviewing process be improved if the referees and editors were no longer to be anonymous or if the referee were blinded to the identity of the author? The former stems from the sometimes voiced criticism that referees hide behind a cloak of anonymity to conceal personal biases, unethical behaviour or incompetence (Bishop, 1984). That has been far from my experience, and my view is certainly shared by most journals. Referees are also authors, and the balance between these functions tends to prevent unreasonable bias by referees. On balance, there is more to be gained by the discipline of anonymity, although that is not to say that there may not be times when a particularly tricky issue could best be resolved by the editor talking directly to the authors. This Journal has not adopted this approach during my chairmanship, but I would not rule it out completely. I have tended to act in the role of mediator and have solved some particularly difficult problems by direct contact with the author on behalf of the editor.

Blinding the editor to the identity of the authors is also sometimes advocated to reduce some supposed biases evoked by the reputation of the authors (Bishop, 1984; Relman \& Angell, 1989). I do not know with certainty of any problems of this kind during my chairmanship and consider that the matter has been exaggerated.

Potential problems of this nature are best avoided by careful choice of editors and referees and the establishment over a period of time of an atmosphere of trust between chairman, editors and referees and, ultimately, authors. No system is infallible. In our quest for ever greater quality of publications we may well be criticized for inflexibility and stuffiness. We do not think the system should be abandoned without something much better to replace it. The proof will be in the Journal's ability to attract papers from the best authors and to be in demand as an essential publication on every nutritionist's bookshelf.

Michael I. GurR

REFERENCES

Bishop, C. T. (1984). How to Edit a Scientific Journal. Philadelphia: ISI Press.

Gurr, M. I. (1989). Editorial. British Journal of Nutrition 61, 3-6.

Relman, A. S. \& Angell, M. (1989). How good is peer review? New England Journal of Medicine 321, 827-829. 